\title{
3 Research Square

\section{Switchable deep eutectic solvent driven micellar extractive fermentation of ultrapure fibrin digesting enzyme from Bacillus subtilis}

Ramya Muniasamy

SASTRA University

Senthilkumar Rathnasamy ( $\sim$ senthilrathna@sastra.ac.in )

SASTRA University

\section{Research Article}

Keywords: Extractive fermentation, Fibrinolytic protease, Surfactants Deep Eutectic Solvents, Micellar two phase extraction

Posted Date: September 14th, 2021

DOI: https://doi.org/10.21203/rs.3.rs-899115/v1

License: (c) (i) This work is licensed under a Creative Commons Attribution 4.0 International License.

Read Full License

Version of Record: A version of this preprint was published at Scientific Reports on January 18th, 2022. See the published version at https://doi.org/10.1038/s41598-022-04788-w. 


\section{Switchable deep eutectic solvent-driven micellar extractive fermentation of ultrapure fibrin digesting enzyme from Bacillus subtilis}

Ramya Muniasamy ${ }^{\mathrm{A}}$, Senthilkumar Rathnasamy ${ }^{\mathrm{B}}$.

Green Separation Engineering Laboratory,

School of Chemical and Biotechnology,

SASTRA Deemed to be University, Thanjavur, Tamil Nadu - 613401

*Corresponding Author

Senthil Kumar Rathnasamy,

Assistant Professor, Green Separation Engineering Laboratory,

SASTRA Deemed to be University, Thanjavur, Tamil Nadu - 613401

Email address: senthilrathna@sastra.ac.in 


\section{ABSTRACT}

Fibrinolytic protease (FLP) is a therapeutic enzyme used in the treatment of thrombolytic diseases. The present study proposed the concept of $\mathrm{pH}$-driven swappable micellar two-phase extraction for the concurrent production and purification of FLP from Bacillus subtilis at cloud point extraction. Extractive fermentation was carried out with a $\mathrm{pH}$ swap mechanism, and FLP was extracted to the top phase by surfactant deep eutectic solvents (SADES). Shrimp waste was chosen as a sustainable low-cost substrate that yielded a maximum protease of $185 \mathrm{U} / \mathrm{mg}$. Six SDESs were synthesized with nonionic surfactants as hydrogen bond donors and quaternary ammonium salts as hydrogen bond acceptors, and their association was confirmed by H1 NMR. Thermophysical investigation of the synthetic SADES was accomplished as a function of temperature. Response surface methodology for extractive fermentation was performed with the concentration of SADES (35\% $\mathrm{w} / \mathrm{v}), \mathrm{Na} 2 \mathrm{SO} 4(15 \% \mathrm{w} / \mathrm{v})$ and $\mathrm{pH}(6.3)$ as variables and the enzyme activity $(248 \mathrm{IU} / \mathrm{mg})$ as a response. Furthermore, purification using gel filtration chromatography was used to quantify the amount of enzyme obtained in the extraction phase (849 IU/ml). After final purification with an anion exchange column, the maximum purity fold (22.32) with enzyme activity (1172 IU/ml) was achieved. The in vitro fibrinolytic activity was confirmed using a fibrin plate assay.

Keywords Extractive fermentation, Fibrinolytic protease, Surfactants Deep Eutectic Solvents, Micellar two-phase extraction 


\section{INTRODUCTION}

Intravascular thrombosis is described as a pathophysiological disorder in which excessive accumulation of blood clots (thrombus) occurs throughout the blood vessels. This chronic condition obstructs blood flow to numerous internal organs and has been reported to be the major cause of cardiovascular abnormalities worldwide $(1,2)$. Conventionally, recombinant therapeutic enzymes such as streptokinase and urokinase are being used widely for treating these thrombotic abnormalities. Due to their undesirable side effects, such as gastrointestinal bleeding and less fibrin specificity $(3,4)$, intense research has been directed at finding alternative microbial fibrinolytic enzymes with better task specificity. Recent investigations have identified Bacillus subtilis as a promising source for the production of specific fibrinolytic proteases (FLPs) that are reported to be safer for therapeutic use $(5,6)$. However, purification of these therapeutically significant enzymes was accomplished with a sequence of downstream operations, such as ammonium sulfate precipitation, ultrafiltration, ion exchange chromatography (7) and affinity chromatography (8). Although these conventional methods have been adapted on a large scale, the addition of subsequent unit operations for enhanced purity makes the process laborious and elevates the cost of the product (9). Furthermore, the harsh environment involved in some purification steps is reported to have an adverse impact on the native state of the product, incurring extensive loss of active enzyme. Therefore, a sustainable and biocompatible purification process that overcomes these limitations is under delve in the modern scientific community.

This delve for alternative purification methods could be readily satisfied by employing extractive fermentation where simultaneous purification of the product from fermentation broth is administered with task-specific solvents (10). Extractive fermentation has been recognized as the most sustainable alternative for enzyme purification in recent decades owing to its advantage of in 
situ product recovery (11). The extraction of products into the solvent-rich phase due to its affinity to the solvent infiltrates the microbial cells and substrates into the raffinate phase, making it a superior technique compared to conventional separation methods (12-15). Earlier investigation reported the usage of neoteric solvents such as ionic liquids and deep eutectics as the most effective phase-forming components in the purification of therapeutic enzymes (16-19). However, the hydrophilicity of these solvents alleviates the demand for higher concentrations, posing potential challenges in making the process viable on a large scale (20). These restrictions were mitigated with the use of micellar-based extraction systems with selective solvents involving surfactants. Earlier investigation was carried out by Luis et al. for the selective purification of alkaloid prodigiosin using Triton X 114, resulting in enhanced recovery (81\%) of the active enzyme (12). Effective recycling of primary phase forming components (Triton X 100 and xylitol) post lipase extraction from pumpkin seeds was previously investigated by Amid et al.(21). Sustainable purification of pectinase (16) by micellar extraction has been reported. Silvia et al investigated the extraction of organic and inorganic arsenic using Triton X 100 in combination with ionic choline chloride. The nonionic surfactant Triton X 100 with the ionic cation choline became an attractive phase-forming component in the industry with low cost and commercial availability (22).

In the current investigation, one-step production and recovery of therapeutic FLP by micellar extractive fermentation was carried out. Six different surfactant deep eutectic solvents (SDESs) were synthesized, and their thermophysical parameters were evaluated. These SDESs were then added at various concentrations to the fermentation broth along with various salts to enable aqueous two-phase formation. The phase ratio and partition coefficient of individual combinations were determined, and SDES with enhanced enzyme recovery was employed to selectively concentrate fibrinolytic protease on a large scale. Back extraction was accomplished 
with a low concentration of potassium chloride, and the enzyme-rich fraction was partially purified by size exclusion chromatography. The enzyme fraction from size exclusion chromatography was loaded onto the anion exchange column to achieve maximum purity. A fibrin plate assay was used to confirm the fibrinolytic activity of the resulting target enzyme. Fig 1, a schematic representation elucidating the entire work.

\section{Results and Discussion}

\subsection{Effect of complex media on FLP production}

Substrate utilization is one of the foremost cost-defining factors in the production of therapeutic enzymes. Some of the underutilized residuals were reported to be used as potential substrates for the large-scale production of commercial and therapeutic enzymes. B. subtilis is the most promising bacteria for the production of fibrinolytic protease, with the optimal yield varying with the type of complex substrate supplied (23). Among the various nitrogen sources, the maximum yield of protease $(185 \mathrm{U} / \mathrm{mg}$ ) was observed to occur with shrimp waste as the primary nitrogen source compared to groundnut cake and cottonseed cake, with moderate enzyme production of $100 \mathrm{U} / \mathrm{mg}$ and $110 \mathrm{U} / \mathrm{mg}$, respectively (Table 1). This might be because shrimp waste is rich in essential minerals such as sodium, potassium, manganese and iron along with a vast reserve of proteins and fats that aids in extensive secondary metabolite production (24). It is also capable of metabolizing its nitrogen content slowly into the media, which favors the maximum production of protease enzymes (25). On the other hand, groundnut cake and cotton seed cake could not sustain the release of nitrogen and were proven incapable of acting as potential nitrogen sources for effective enzyme yields. An identical investigation carried out by Lang et al concluded that shrimp shell powder acts as a potential inducer of alkaline protease production from Bacillus subtilis (26). Similar investigations on the production of fibrinolytic protease with various complex 
substrates, such as soybean filtrate (27), fodder yeast (5) and Cassava starch (28), have comparatively yielded lower amounts of enzyme than shrimp waste.

\subsection{Thermophysical characterization of SDES}

Surfactant-DES synthesized by combining Triton X 100, Tween 80 (nonionic surfactants) with quaternary ammonium salts choline chloride, tetrabutyl ammonium bromide, and tetrabutyl ammonium chloride was heated in the appropriate molar ratio and remained homogenous at room temperature (Fig 2). This exposed that the SDES was capable of effective extraction of therapeutic enzymes and was well established as a micellar-based aqueous two-phase system.

\subsubsection{Density}

The density of the synthesized SDES was measured as a function of temperature in the range of 293-323 K. From Fig 3A, it was evident that a linear increase in density was observed with a proportional decrease in temperature and increase in the molar ratio of DES. As the temperature increases, the intermolecular interaction between the corresponding HBA and HBD becomes less dense due to thermal expansion (29). The highest density was recorded for TW:TBAB (1.146 g

$\left.\mathrm{cm}^{-3}\right)$, and the lowest was recorded for TX:CCL $\left(1.024 \mathrm{~g} \mathrm{~cm}^{-3}\right)$ at $323 \mathrm{~K}$. The order of density at both extremities of temperature was found to be identical as follows: TX:CCL $<$ TX:TBAC $<$ TX:TBAB < TW:CCL < TW:TBAC < TW:TBAB. The extraction of the fibrinolytic protease was observed to be critically influenced by the density of the corresponding SDES under investigation. The lowest molecular weight of ionic choline resulted in a lower density SDES with both Triton and Tween. Tween interactions were found to be more effective with quaternary ammonium salts, resulting in a higher density compared to Triton (30). Denser eutectic mixtures tend to accumulate in the top phase, virtually leaving limited space for the enzyme, resulting in a lower yield of product. In contrast, SDES with low density consumes a large amount of salt, forming a biphasic 
system with a low phase ratio and leading to infiltration of a large amount of enzyme to a salt-rich phase (ref). Therefore, it could be conclusive from the above postulations that SDES with moderate density (TX: CCL) acts selectively toward effective extraction of fibrinolytic protease. A similar investigation using a hydrolow transition-temperature mixture for the biomass pretreatment of lignin concluded effective product recovery using mixtures with moderate density (31).

\subsubsection{Refractive index}

The refractive index of the synthesized SDES was observed to decrease linearly with increasing temperature. The extraction of the DES was improved with a lower refractive index. The refractive index value of TW:TBAB was found to be the highest (1.34), while the TX:CCL mixture had the lowest value (1.292). The intermolecular cohesive energy between HBA and HBD tends to be higher for larger molecular weight surfactants, resulting in SDES with a high refractive index. On the other hand, lower molecular weight surfactant counterparts form SDES with a low refractive index due to the scarcity of hydrogen bonding between the corresponding HBA (32). SDES with a higher refractive index is observed to have an elevated molar volume and thus acts inert while salting out with minimal extraction efficiency. In contrast, SDES with a low refractive index and fewer intermolecular interactions has a low salting out volume, providing a minimum partitioning effect. Therefore, SDES with a moderate refractive index is preferable because it provides an improved free volume for the target molecule, enhancing the extraction with a better salting out coefficient (ref). The decreasing order of refractive index was as follows: TW: TBAB> TW: TBAC> TW: CCL> TX: TBAB>TX: TBAC>TX: CCL (Fig 3B).

\subsubsection{Viscosity}


The viscosity of all SDESs was measured in relation to temperature in the range of $293-323$ K. It could be observed that the viscosity of all the mixtures decreased in a nonlinear fashion as the temperature increased. This is because of the reduction in noncovalent interactions between HBA and HBD in the SDES at higher temperatures, decreasing the surface tension of the mixture (33). Similar to the investigation performed by Gajardo et al., the molecular weight of the corresponding HBA and HBD was observed to have a substantial influence even on the viscosity of the mixture (34). Surfactants (Tween 80) with high molecular weights associate more strongly with quaternary ammonium salts (0.583 Pa.s), making the resultant SDES more viscous than their low molecular weight counterparts (Triton X 100) (0.327 Pa.s). Additionally, viscous DESs have low product retention capacity due to their inability to generate void space for target molecule accommodation. DESs with low viscosity exhibit poor salting out capability, resulting in poor phase formation (35). Therefore, SDES with moderate viscosity is assumed to act selectively in concentrating fibrinolytic protease to the top phase. The viscosity of the SDES under investigation follows the order of TX: CCL < TX: TBAC < TX: TBAB < TW: CCL < TW: TBAC < TW: TBAB (Fig 3C). An identical investigation carried out by Wang et al. for choline chloride-based DESs concluded that the addition of glycerol as an HBD results in a higher viscosity than the ethylene glycol counterparts. This is due to the additional hydroxyl group in glycerol enabling a stronger binding strength between $\mathrm{HBA}$ and $\mathrm{HBD}$, thus resulting in a deviation in its physical properties (36).

\subsubsection{Binodal curve determination of SDES}

The critical concentrations of both SDES and salt were observed to have greater significance in two-phase formation and product retention. This effect could be elucidated with binodal curve determination by the cloud point titration method (37). The binodal curve between 
the individual SDES under investigation and its corresponding salt is shown in Fig 3D. The extended curve obtained for high-density SDES signifies its excess salting out capability, making them suitable for liquid-liquid extraction applications. In contrast, low-density SDES requires less salt to achieve consecutive cloud points, resulting in a narrow biphasic region. The SDES with reasonable density is observed to have sufficient salting-out volume, resulting in a large two-phase region. The stability of the biphasic system was influenced by the entropy change of SDES and salt combination. The phase formation for the SDES and salt occurred in the following order: TX: TBAB > TW: CCL > TX: TBAC > TX: CCL > TW: TBAC > TW: TBAB.

\subsubsection{H H $^{1}$ NM analysis of synthesized SDES:}

Analysis of $\mathrm{H}^{1} \mathrm{NMR}$ analysis of the synthesized SDES provides the details of the interaction between both HBA and HBD that results in the formation of the corresponding eutectic mixture. The distributed occurrence of peaks in the graphs (Fig S1 - S6) signifies the native state of HBA and HBD with certain indefinite peaks denoting the noncovalent association between them. In addition, the indeterminate sharp peaks distributed throughout signify that the noncovalent associations that occurred at the eutectic temperature are strong, making the mixture stable at room temperature.

\subsection{Effect of SDES on fibrinolytic protease extraction}

Each phase composition was determined by titrating all SDES and salt concentrations (Table 2). The nonionic surfactant Triton $X 100$ with choline chloride (TX:TBAC) (1:1)) as HBD and HBA, respectively, was proven to be effective in the extraction of therapeutic fibrinolytic protease into the SDES-rich top phase compared with other counterparts. The specificity of SDES in isolating the enzyme was greatly influenced by the amount of protease present in broth. Denser SDES exhibits a lower partition coefficient, as the void space for accommodation of the protease 
in the top phase is limited, enabling its infiltration into the bottom phase. A lower density of SDES requires more salt to enable two-phase formation as a result of the low salting out ability, leading to a low volume and partition coefficient. SDES with moderate density improved the extraction of FLP into the micellar-rich phase with a better partition coefficient of 2.17 (Table 3). The nonionic surfactants Tween 80 and Triton X 100 enhance the enzyme activity at higher concentrations compared to ionic surfactants (38). The partition coefficient follows the descending order: TX: CCL<TX: TBAC<TX: TBAB< TW: CCL<TW: TBAC<TW: TBAB (Fig 4). A similar investigation by Silva et al Triton X 100 with choline chloride as the phase forming component required 19 times less ammonium pyrimidine dithiocarbonate as the primary extracting agent for concentrating arsenic than conventional polymer-based ATPSs (22).

Salt selection in cloud point extraction for micellar ATPSs is essential, as it promotes phase separation. The volume ratio of the micellar and aqueous phases is greatly influenced by the salting-out effect (39). Sodium sulfate, potassium dihydrogen phosphate, and sodium dihydrogen phosphate were investigated as potential chaotropic agents for micellar ATPS formation. Sodium sulfate with moderate ionic strength (salting out) was observed to enhance the two-phase system with a better phase volume and cloud point. The higher ionic strength of inorganic salt forms the phase immediately, displays a wider biphase region and does not denature protease. Due to the ionic strength, phase separation has been observed to occur in the order of $\mathrm{NaH}_{2} \mathrm{PO}_{4}>\mathrm{Na}_{2} \mathrm{SO}_{4}>$ $\mathrm{KH}_{2} \mathrm{PO}_{4}>$, which closely follows the Hofmeister series of cations and anions and encourages a salting-out nature.

\subsection{Effect of swappable pH at cloud point extraction}

Micellar-based ATPSs are formed when a cloudy appearance takes place, and the homogeneity of the mixture is disrupted at the critical micellar concentration of salt and SDES (40). In the 
current investigation, a swappable $\mathrm{pH}$-assisted micellar aqueous two-phase system was accomplished with TX:TBAC with $80 \%$ extraction efficiency. Triton X 100 does not easily ionize in an aqueous solution, and with a cloud temperature of $65^{\circ} \mathrm{C}$, it functions as a better phase forming alternative at room temperature (41). The $\mathrm{pH}$ of the system affects the partitioning of biomolecules by altering the charge and surface properties of surfactants. When the phase forming components were added to the broth, the protein competed for each other to move into the micellar rich phase based on its hydrophobicity. The greater the hydrophobicity of the protein is, the greater the affinity toward the micellar-rich DES phase. The swap in $\mathrm{pH}$ to 6 by addition of $0.1 \mathrm{M} \mathrm{HCl}$ altered the protein charge so that the positive and open structure of the protein became enclosed in the SDES-rich phase, as Yu et al reported a switchable $\mathrm{pH}$ of the aqueous phase to form biphasic from the monophasic region (42). The recovery of fibrinolytic protease was maximum at optimum $\mathrm{pH}$ 6 with a partition coefficient of 2.17 because the enzyme remained active and stable at acidic $\mathrm{pH}$. The cloud point and micelle size were not affected by $\mathrm{pH}$ in the range of 2 to 10 (43). The decrease in $\mathrm{pH}$ with the increase in the temperature until $50^{\circ} \mathrm{C}$ favored extraction into the SDES-rich top phase. The extraction at pH 5 made the broth more acidic, and the enzyme lost its stability. At pH 7, an interface layer precipitating the product occurred. At $\mathrm{pH} 8$, the protein was almost equal to its $\mathrm{pI}$, which makes the protein have a net charge of zero (44). SDES was considered neutral, and the change in $\mathrm{pH}$ was not affected, as the zwitterion detergent blended with ionic salt formed ambivalent surfactant micelles (41). The pretreatment of biomass at less than $\mathrm{pH} 7$ solubilized the hemicellulose fractions by adding $\mathrm{HCl}$ or $\mathrm{H}_{2} \mathrm{SO}_{4}(45)$.

\subsection{Optimization of micellar extractive fermentation using SDES}

All the independent factors that have a significant influence on the selective recovery of fibrinolytic protease were chosen for optimization. The specific activity of the resulting enzyme 
fraction remains distributed between $208 \mathrm{IU} / \mathrm{mg}$ and $245 \mathrm{IU} / \mathrm{mg}$. Notable is the substantial effect of both $\mathrm{pH}$ and SDES concentration on the recovery of active enzymes. Furthermore, it could clearly be observed that the reduced concentration of salt has a significant effect on the recovery of enzymes, thus denoting its unsubstituted role in the selective partitioning of fibrinolytic protease. An optimal enzyme activity of $248 \mathrm{IU} / \mathrm{mg}$ was achieved with $\mathrm{Na}_{2} \mathrm{SO}_{4}(15 \%$ w/w $)$ and SDES (38\% w/w) along with an optimal pH of 6.0 (Fig 5).

\subsection{Preparative purification of FLP by size exclusion chromatography}

The extractive fermentation sample was loaded on Sephadex G-15 for quantification.

The separation was based on the molecular size of the molecules. The run was optimized with a $1.0 \mathrm{ml} / \mathrm{min}$ sample flow rate, which gave the sample adequate time to interact with the stationary phase. The resolution of the column was increased when the flow rate was reduced and reflected on the plate numbers. The peak eluted fraction retention time was 10 minutes, with a maximum activity of $849 \mathrm{IU} / \mathrm{ml}$ (Table 4). The retention volume and number of theoretical plates were estimated to be $24 \mathrm{ml}$ and $3.2 \mathrm{NTU}$. The eluted fraction with maximum activity (Fig 6A) was collected and further purified using a DEAE anion exchange column.

\subsection{Ultra purification of fibrinolytic protease with anion exchange chromatography}

The DEAE-Sepharose anion exchange column was equilibrated with the desired $\mathrm{pH}(8.2)$ and ionic strength (equilibration buffer) so that the column was prepared for binding or adsorption of the target molecules. The sample was injected at a flow rate of $1 \mathrm{ml} / \mathrm{min}$ and dissolved into the column, where the molecules with suitable charge displaced the counter ions in the column and bound to it. Then, a washing step was performed with equilibration buffer to remove the unbound molecules. The next step was elution accomplished by eluting buffer by increasing the ionic strength (1 M $\mathrm{NaCl})$ and altering the $\mathrm{pH}(8.5)$. Desorption of target molecules was achieved by altering the $\mathrm{pH}$ 
with increasing salt concentration, and the molecules eluted out based on the binding strength. The eluted fraction with a retention time of 10 minutes was collected, and the fibrinolytic protease activity was found to be $1172 \mathrm{IU} / \mathrm{ml}$ (Table 4). The recovery of fractions was found to be $90 \%$ (Fig 6B).

\subsection{Fibrin plate assay}

The extracted enzyme was screened for fibrinolytic activity by fibrin plate assay for the hydrolysis of fibrin. Ten microliters of the crude, purified enzyme was added to the well, and the zone of clearance was found to be 1.5 and $2.0 \mathrm{~cm}$. Fig. 7 clearly shows that the ultrapure enzyme fraction was capable of degrading fibrin effectively.

\section{MATERIALS AND METHODS}

\subsection{Chemical and reagents}

Triton X 100 (9002-93-1), choline chloride (67-48-1), tetrabutylammonium bromide (1643-19-2), tetrabutylammonium chloride (1112-67-0), bovine serum albumin (A7030), and Tween 80 (9005-65-6) were purchased from Sigma-Aldrich with 99.9\% purity. Peptic digests of animal tissue, yeast extract, $\mathrm{Na}_{2} \mathrm{SO}_{4}, \mathrm{MgSO}_{4}, \mathrm{NH}_{4} \mathrm{Cl},\left(\mathrm{NH}_{4}\right)_{2} \mathrm{SO}_{4}, \mathrm{~K}_{2} \mathrm{HPO}_{4}, \mathrm{CaCl}_{2}, \mathrm{Na}_{2} \mathrm{CO}_{3}$, and Luria Bertani broth media were procured from Himedia, India with $<95 \%$ purity.

\subsection{Screening and complex media preparation:}

Bacillus subtilis strain No - 441 was purchased from MTCC, Chandigarh. The purchased strain was plated on skimmed milk agar and incubated at $37^{\circ} \mathrm{C}$ for 24 hours. The colony with maximum proteolytic activity (forming a clear zone in skimmed milk agar) was subcultured on skim milk agar to enhance protease activity (46). The pure colony thus isolated was used to inoculate the seed culture in nutrient broth $(5.0 \mathrm{~g} / \mathrm{L})$, yeast extract $(1.5 \mathrm{~g} / \mathrm{L})$, and sodium chloride $(5.0 \mathrm{~g} / \mathrm{L}))$ and incubated overnight (47). 
Various complex sources, such as groundnut cake, cottonseed cake, and shrimp wastes, were purchased from the local market, sterilized with $0.1 \%$ sodium hypochlorite solution and dried in a hot air oven. These dry complex sources were then macerated with $20 \mathrm{mM}$ Tris-HCl buffer and centrifuged at $10000 \mathrm{rpm}$. The supernatant thus obtained was considered a complex substrate (for enzyme production) and was stored at $-4^{\circ} \mathrm{C}$ for further use. The production media was prepared by mixing the complex substrates (1\% v/v) with glucose (10 g/L), $\mathrm{NH}_{4} \mathrm{Cl}(3 \mathrm{~g} / \mathrm{L}), \mathrm{MgSO}_{4}$ ( $2 \mathrm{~g} / \mathrm{L}), \mathrm{Na}_{2} \mathrm{CO}_{3}(0.6 \mathrm{~g} / \mathrm{L})$, and $\mathrm{CaCl}_{2} .2 \mathrm{H}_{2} \mathrm{O}(5 \mathrm{~g} / \mathrm{L})$ at $\mathrm{pH} 7.2$ and sterilizing at $1210^{\circ} \mathrm{C}$ for $15 \mathrm{~min}$ as described by Cho et al. (48). The sterile medium was then inoculated with $1 \%$ overnight grown seed inoculum and incubated for $21 \mathrm{~h}$ at $120 \mathrm{rpm}$.

\subsection{Synthesis and thermophysical characterization of surfactant-based deep eutectic solvents (SDESs)}

The present study involved the synthesis of six surfactant-based DESs (SDESs) with Triton X 100 and Tween 80 as hydrogen bond donors (HBDs) and ammonium salts as hydrogen bond acceptors (HBAs). Individual SDESs were synthesized by mixing both HBA and HBD in a defined molar ratio (1:1) and heating the mixture at $800^{\circ} \mathrm{C}$ with continuous stirring. The resulting dense and transparent liquid is described as a eutectic mixture. The stability of the SDES solution thus formed was observed for 45 days at room temperature in a vacuum desiccator to avoid moisture entrapment. The molar composition of all nine SDES along with their abbreviations is depicted in Table 2.

The density, viscosity, and refractive index of all SDESs formed were measured in the temperature interval of 273-323 K. A rudolf digital density meter (DDM 2910) with an in-built thermocouple for temperature control was used to measure the density of all eutectic mixtures. The viscosity of all SDESs was quantified using a Brooke field LV II+ Digital Viscometer. The thermal 
jacket attached to the viscometer was regulated by an external oil bath. The refractive index of all eutectic mixtures was calculated by Atago (MASTER-PM) hand-held refractometer along with the sodium D1 line. All instruments used were calibrated with deionized water before measurement.

The $\mathrm{H}^{1}$ NMR of all SDES was determined with a $300 \mathrm{MHz}$ BRUKER AVANCE II Spectrophotometer equipped with a $5 \mathrm{~mm}$ BBO probe. $\sim 8 \mathrm{mg}$ of SDES was dissolved in $500 \mu \mathrm{l}$ of $\mathrm{D}_{2} \mathrm{O}$ in quartz NMR tubes and ultrasonicated for 5 minutes. Resonance at $298.18 \mathrm{~K}$ was observed, and progress was recorded with the sequence library Topspin 3.2. (Bruker biospin, Switzerland).

\subsection{Binodal curve determination of SDES:}

Ten milliliters of aqueous SDES (80\% (v/v)) was added to a fresh separation funnel, and aqueous sodium sulfate $(20 \%(\mathrm{w} / \mathrm{v}))$ was added dropwise until a cloudy appearance in the transparent solution. The milky solution was left undisturbed to enable the formation of two distinct phases. The phases were separately collected, and the mass of individual phases was noted by a Shimadzu BL-220H weighing balance. The procedure was repeated after diluting the earlier cloud point to the homogenous monophasic solution by dropwise addition of water until the extract volume was minimal. The mass fractions of SDES and salt observed at each cloud point were plotted individually on the $\mathrm{X}$ - and $\mathrm{Y}$-axes to obtain the binodal curve of SDES as described by capela et al. (49).

\subsection{Micellar-based Extractive Fermentation (MEF) of fibrinolytic protease}

Extractive fermentation was carried out on a $14 \mathrm{~h}$ batch culture (culture in log phase of production) to obtain an effective yield of fibrinolytic protease. In a batch experiment, sterile SDES $(80 \% \mathrm{w} / \mathrm{v})$ and salt $(20 \% \mathrm{w} / \mathrm{v})$ were weighed and added to the broth and vigorously agitated until the formation of the cloud point. The $\mathrm{pH}$ of the milky heterogeneous mixture was altered 
from 7.2 to 6 by adding $0.1 \mathrm{M} \mathrm{HCl}$ aseptically, and the content was left undisturbed until the formation of two distinct phases. Once separation was achieved with a well-defined boundary, individual phase components were aspirated carefully without disturbing the intermediate layer. The total volume of the system and the corresponding individual volume of the two phases were noted. The phase ratio of individual SDES and salt combinations were evaluated with the following equation:

$$
P_{r}=\frac{V_{t o p}}{V_{\text {bottom }}}
$$

where $\mathrm{P}_{\mathrm{r}}$ denotes the phase ratio, $\mathrm{V}_{\text {top }}$ denotes the volume of the top phase and $\mathrm{V}_{\text {bottom denotes the }}$ volume of the bottom phase.

The enzyme recovered in individual phases was determined by its corresponding fibrinolytic activity as described by da siva et al. (50). The partition coefficient $(\mathrm{K})$ of the system was determined as the ratio between the corresponding concentrations of fibrinolytic protease in the top and bottom phases. The selectivity of individual SDESs toward efficient recovery of the enzyme could be determined with the partition coefficient values. The partition coefficient K was determined by

$$
K=\frac{C_{\text {top }}}{C_{\text {bottom }}}
$$

where $\mathrm{K}=$ partition coefficient, $\mathrm{C}_{\mathrm{top}}=$ concentration of protease in the top phase $(\mathrm{mg} / \mathrm{ml})$, and $\mathrm{C}_{\text {bottom }}=$ concentration of protease in the bottom phase $(\mathrm{mg} / \mathrm{ml})$. The purity factor $(\mathrm{P})$ of the enzyme recovered in the top phase was interpreted as the ratio of FLP activity in the top phase to the corresponding activity in the crude phase. 


$$
P=\frac{\frac{C_{t o p}}{T_{\text {top }}}}{\frac{C_{\text {crude }}}{T_{\text {crude }}}}
$$

where $\mathrm{P}=$ purity factor, $\mathrm{T}_{\text {top }}=$ total protein concentration in the top phase $(\mathrm{mg} / \mathrm{ml}), \mathrm{C}_{\text {crude }}=$ fibrinolytic protease concentration of the crude extract $(\mathrm{mg} / \mathrm{ml})$, and $\mathrm{T}_{\text {crude }}=$ total protein concentration of the crude extract $(\mathrm{mg} / \mathrm{ml})$. The yield $(\%)$ of fibrinolytic protease $\left(\mathrm{Y}_{\mathrm{flp}}\right)$ was calculated as the proportion of fibrinolytic activity in the top phase to the fibrinolytic activity in the initial crude in percentage.

$$
Y_{f l p}=\left(\frac{C_{\text {top }}}{C_{\text {crude }}}\right) * 100
$$

The specific activity (S) of the enzyme was calculated by the ratio of protease activity in the top phase to the total protein in the crude.

$$
S=\frac{C_{\text {top }}}{\text { Tcrude }}
$$

\subsection{Optimization of Micellar Extractive Fermentation by Response Surface Methodology}

The influence of essential components on the effective recovery of fibrinolytic protease by micellar extractive fermentation was determined by response surface methodology. The statistical significance of individual variables on the recovery of protease was determined using a central composite design (CCD) with the help of Design Expert (v10.1 Stat-ease, Minneapolis USA). The SDES concentration ( 25 to $45 \% \mathrm{v} / \mathrm{v}$ ), $\mathrm{K}_{2} \mathrm{HPO}_{4}$ concentration ( $5 \%$ to $15 \% \mathrm{w} / \mathrm{v}$ ), and $\mathrm{pH}$ of the system (4.5 to 7.5 ) were the most influential factors chosen for optimization (ref). The fibrinolytic activity in the SDES-rich top phase was selected as the response factor. A set of 32 experiments with 6 center points, 2 axial and a radial point were formulated. Each trial was conducted in a 250 $\mathrm{ml}$ flask filled with $100 \mathrm{ml}$ of fresh culture media. A $1 \% \mathrm{v} / \mathrm{v}$ seed culture was inoculated, incubated at $40^{\circ} \mathrm{C}$ and $150 \mathrm{rpm}$, and subjected to batch fermentation for 14 hours. Following incubation, 
aqueous solutions of SDES and $\mathrm{K}_{2} \mathrm{HPO}_{4}$ were added at concentrations corresponding to the respective trials and left undisturbed until the formation of two distinct phases. The amount of enzyme recovered from both phases was determined by fibrinolytic activity determination.

\subsection{Back extraction of SDES}

The fibrinolytic protease-rich SDES phase was back-extracted to recover the enzyme in its native form. The SDES-rich phase recovered from the previous step was transferred to a sterile flask, and an equal volume of fresh aqueous potassium chloride solution (15\% W/V) was added and incubated with reduced agitation (51). The van der wall force between the SDES and enzyme became destabilized, leading to the infiltration of active enzyme to the salt-rich phase. The excess water in the SDES recovered was removed, and the solvent was reused for a fresh batch of extraction cycles. The amount of SDES recovered ( $\mathrm{R}_{\mathrm{SDES}}$ ) was determined as detailed by Mehrrnoush et al using the following equation (16):

$$
R_{\text {SDES }}=\frac{A_{\text {final }}}{A_{\text {initial }}} * 100
$$

where $A_{\text {final mass }}$ indicates the mass of SDES recovered and $A_{\text {initial mass }}$ is the total mass of SDES introduced into the system.

\subsection{Preparative purification of fibrinolytic protease by size exclusion chromatography}

A $5 \mathrm{ml}$ Sephadex G-15 Size Exclusion chromatography column (Akta Prime plus) was used for preparative purification of the recovered enzyme. Prior to sample injection, $20 \mathrm{mM}$ phosphate buffer at $\mathrm{pH}$ 7) with a flow rate of $2 \mathrm{ml} / \mathrm{min}$ (flow rate maintained constant during the process) was used for column equilibration. The crude extract obtained from the back extraction step was loaded, and elution of the protein molecules was achieved by passing the same equilibration buffer (52). Individual fractions showing the peaks observed in the chromatogram were collected, and eluent showing maximum fibrinolytic activity was designated as the fraction of interest. The 
efficiency of the column toward separation of fibrinolytic protease from other proteins was determined using the number of theoretical plates per meter (NTP).

$$
N T P=16\left(\frac{t_{r}}{W_{b}}\right)^{2}
$$

where NTP $=$ number of theoretical plates, $t_{R}=$ retention time, and $\mathrm{W}_{\mathrm{b}}=$ peak width. Similarly, the binding efficiency was determined by calculating the retention volume with the following equation.

$$
R_{v}=R_{t} * W_{b}
$$

where $\mathrm{R}_{\mathrm{V}}=$ retention volume, $\mathrm{R}_{\mathrm{t}}=$ retention time, $\mathrm{W}_{\mathrm{b}}=$ base width of the peak

\subsection{Ultra purification by DEAE-anion exchange chromatography}

The eluent fraction obtained through preparative purification was ultrapurified with a $5 \mathrm{ml}$ DEAE Sepharose anion exchange chromatography column (GE, AKTA prime plus). The column was equilibrated with $20 \mathrm{mM}$ Tris- $\mathrm{HCl}$, pH 8.2 buffer until zero baseline was achieved. Then, the sample was loaded through the sample port, which entered the column along with the equilibration buffer (53). All undesirable molecules that did not bind to the column were removed with an equilibration buffer. Elution was accomplished by passing the elution buffer $50 \mathrm{mM}$ Tris- $\mathrm{HCl}$ and $1 \mathrm{M} \mathrm{NaCl}, \mathrm{pH} 8.5$, as a gradient along with equilibration buffer. Due to a change in the buffer ionic strength, the target enzymes bound to the matrix were eluted serially depending on their binding strength to the column matrix. The fraction exhibiting the highest enzyme activity was regarded as the ultrapure enzyme fraction. The yield of the ultrapure enzyme fraction was calculated with the following equation.

\subsection{Fibrin plate assay}

The fibrinolytic activity of the ultrapure fraction of enzyme obtained from anion exchange chromatography was measured using the fibrin plate degradation method as mentioned by cruz et 
al. (54). The fibrin gel was prepared by adding $10 \mathrm{ml}$ of fibrinogen $(0.5 \% \mathrm{w} / \mathrm{v})$ along with $0.1 \mathrm{ml}$ of thrombin (50 NIH U/ml) into a $15 \mathrm{ml}$ agarose gel (agarose 1\% w/v) and allowed to solidify in a petri plate. A hole of $3 \mathrm{~mm}$ diameter was punctured on the gel and loaded with $10 \mu \mathrm{l}$ of crude and ultrapure fractions of enzymes. The plate was incubated for 12 hours at $37^{\circ} \mathrm{C}$, and the zone of clearance with fibrin degradation was measured carefully.

\section{Acknowledgment:}

The authors are grateful for the support provided by the Department of Science and Technology, India, for providing a research grant through Women scientist-A (WOS-A/CS-

57/2019 (G)) to accomplish the investigation. The authors also acknowledge the Bioseparation Laboratory, School of Chemical and Biotechnology, SASTRA Deemed to be University, Thanjavur, Tamil Nadu - 613 401, India for providing the chromatography facility.

\section{References}

1. Rathnasamy SK, Durai A, Vigneshkumar AA, Purushothaman C, Rajendran DS, Chandramouliswaran $\mathrm{K}$. One-pot simultaneous production and sustainable purification of fibrinolytic protease from Bacillus cereus using natural deep eutectic solvents. Scientific Reports. 2020;10(1):13356. 2. D D, S JN, S MK, C SD. Novel Fibrinolytic Protease Producing Streptomyces radiopugnans VITSD8 from Marine Sponges. Mar Drugs. 2019;17(3):164.

3. Tian Z, Li B, Guo L, Wu M, Fu T, Cheng H, et al. Purification and biochemical characterization of a novel fibrinolytic enzyme, PSLTro01, from a medicinal animal Porcellio scaber Latreille. International Journal of Biological Macromolecules. 2015;80:536-46.

4. Silva GMM, Bezerra RP, Teixeira JA, Porto TS, Lima-Filho JL, Porto ALF. Fibrinolytic protease production by new Streptomyces sp. DPUA 1576 from Amazon lichens. Electronic Journal of Biotechnology. 2015;18(1):16-9.

5. Moharam M, El-bendary M, El-Beih F, Hassnin S, Abo Elsoud M, Azzam M, et al. Optimization of fibrinolytic enzyme production by newly isolated Bacillus subtilis Egy using central composite design. Biocatalysis and Agricultural Biotechnology. 2018;17.

6. Pant G, Prakash A, Pavani JVP, Bera S, Deviram GVNS, Kumar A, et al. Production, optimization and partial purification of protease from Bacillus subtilis. Journal of Taibah University for Science. 2015;9(1):50-5.

7. Kim C, Ri K, Choe S. A novel fibrinolytic enzymes from the Korean traditional fermented foodJotgal: Purification and characterization. Journal of Food Biochemistry. 2020;44. 
8. Taneja K, Kumar Bajaj B, Kumar S, Dilbaghi N. Process optimization for production and purification of novel fibrinolytic enzyme from Stenotrophomonas sp. KG-16-3. Biocatalysis and Biotransformation. 2019;37(2):124-38.

9. Vicente FA, Santos JHPM, Pereira IMM, Gonçalves CVM, Dias ACRV, Coutinho JAP, et al. Integration of aqueous (micellar) two-phase systems on the proteins separation. BMC Chemical Engineering. 2019;1(1):4.

10. Alves RO, de Oliveira RL, da Silva OS, Porto ALF, Porto CS, Porto TS. Extractive fermentation for process integration of protease production by Aspergillus tamarii Kita UCP1279 and purification by PEGCitrate Aqueous Two-Phase System. Preparative biochemistry \& biotechnology. 2021:1-8.

11. Anbarasan P, Baer ZC, Sreekumar S, Gross E, Binder JB, Blanch HW, et al. Integration of chemical catalysis with extractive fermentation to produce fuels. Nature. 2012;491(7423):235-9.

12. Chávez-Castilla L, Aguilar O. An integrated process for the in situ recovery of prodigiosin using micellar ATPS from a culture of Serratia marcescens. Journal of Chemical Technology and Biotechnology. 2016;91.

13. Cruz Filho RFd, dos Santos JG, Palheta RA, Santos-Ebinuma VC, Viana Marques DdA, Teixeira MFS. Comparison of conventional and extractive fermentation using aqueous two-phase system to extract fibrinolytic proteases produced by Bacillus stearothermophilus DPUA 1729. Preparative biochemistry \& biotechnology. 2021;51(2):191-200.

14. LiU S, Li Z, Yu B, Wang S, Shen Y, Cong H. Recent advances on protein separation and purification methods. Advances in Colloid and Interface Science. 2020;284:102254.

15. Silva OSd, Alves RO, Porto TS. PEG-sodium citrate aqueous two-phase systems to in situ recovery of protease from Aspergillus tamarii URM4634 by extractive fermentation. Biocatalysis and Agricultural Biotechnology. 2018;16:209-16.

16. Amid M, Murshid FS, Manap MY, Hussin M. A Novel Aqueous Micellar Two-Phase System Composed of Surfactant and Sorbitol for Purification of Pectinase Enzyme from <i>Psidium guajava</i> and Recycling Phase Components. BioMed Research International. 2015;2015:815413.

17. Lin YK, Show PL, Yap YJ, Ariff AB, Mohammad Annuar MS, Lai OM, et al. Production of $Y$ cyclodextrin by Bacillus cereus cyclodextrin glycosyltransferase using extractive bioconversion in polymer-salt aqueous two-phase system. Journal of Bioscience and Bioengineering. 2016;121(6):692-6.

18. Torres FAE, de Almeida Francisco AC, Pereira JFB, Santos-Ebinuma VdC. Imidazolium-based ionic liquids as co-surfactants in aqueous micellar two-phase systems composed of nonionic surfactants and their aptitude for recovery of natural colorants from fermented broth. Separation and Purification Technology. 2018;196:262-9.

19. Choi YH, Verpoorte R. Green solvents for the extraction of bioactive compounds from natural products using ionic liquids and deep eutectic solvents. Current Opinion in Food Science. 2019;26:87-93.

20. Paiva A, Craveiro R, Aroso I, Martins M, Reis RL, Duarte ARC. Natural Deep Eutectic Solvents Solvents for the 21st Century. ACS Sustainable Chemistry \& Engineering. 2014;2(5):1063-71.

21. Amid M, Manap M, Hussin M, Mustafa S. A Novel Aqueous Two Phase System Composed of Surfactant and Xylitol for the Purification of Lipase from Pumpkin (Cucurbita moschata) Seeds and Recycling of Phase Components. Molecules. 2015;20(6):11184-201.

22. Silva SJBE, Ferreira GMD, Neves HP, De Lemos LR, Rodrigues GD, Mageste AB. Use of aqueous two-phase systems formed by Triton $\mathrm{X}$ and choline chloride for extraction of organic and inorganic arsenic. Separation and Purification Technology. 2021;263:118082.

23. Chang $\mathrm{C}-\mathrm{T}$, Wang $\mathrm{P}-\mathrm{M}$, Hung $\mathrm{Y}-\mathrm{F}$, Chung $\mathrm{Y}-\mathrm{C}$. Purification and biochemical properties of a fibrinolytic enzyme from Bacillus subtilis-fermented red bean. Food Chemistry. 2012;133(4):1611-7.

24. Mizani M, Aminlari M, Khodabandeh M. An Effective Method for Producing a Nutritive Protein Extract Powder from Shrimp-head Waste. Food Science and Technology International - FOOD SCI TECHNOL INT. 2005;11:49-54. 
25. Bajaj BK, Sharma N, Singh S. Enhanced production of fibrinolytic protease from Bacillus cereus NS-2 using cotton seed cake as nitrogen source. Biocatalysis and Agricultural Biotechnology. 2013;2(3):204-9.

26. Wang S-L, Yeh P-Y. Production of a surfactant- and solvent-stable alkaliphilic protease by bioconversion of shrimp shell wastes fermented by Bacillus subtilis TKU007. Process Biochemistry. 2006;41(7):1545-52.

27. Sales AE, de Souza FASD, Teixeira JA, Porto TS, Porto ALF. Integrated Process Production and Extraction of the Fibrinolytic Protease from Bacillus sp. UFPEDA 485. Applied Biochemistry and Biotechnology. 2013;170(7):1676-88.

28. Pan S, Chen G, Zeng J, Cao X, Zheng X, Zeng W, et al. Fibrinolytic enzyme production from lowcost substrates by marine Bacillus subtilis: Process optimization and kinetic modeling. Biochemical Engineering Journal. 2018;141.

29. Yadav A, Trivedi S, Rai R, Pandey S. Densities and dynamic viscosities of (choline chloride+glycerol) deep eutectic solvent and its aqueous mixtures in the temperature range (283.15363.15)K. Fluid Phase Equilibria. 2014;367:135-42.

30. Patel V, Bharatiya B, Ray D, Aswal VK, Bahadur P. Investigations on microstructural changes in $\mathrm{pH}$ responsive mixed micelles of Triton $\mathrm{X}-100$ and bile salt. Journal of Colloid and Interface Science. 2015;441:106-12.

31. Yiin CL, Quitain AT, Yusup S, Uemura Y, Sasaki M, Kida T. Sustainable green pretreatment approach to biomass-to-energy conversion using natural hydro-low-transition-temperature mixtures. Bioresource Technology. 2018;261:361-9.

32. Shahbaz K, Bagh FSG, Mjalli FS, AINashef IM, Hashim MA. Prediction of refractive index and density of deep eutectic solvents using atomic contributions. Fluid Phase Equilibria. 2013;354:304-11.

33. Florindo C, Romero L, Rintoul I, Branco LC, Marrucho IM. From Phase Change Materials to Green Solvents: Hydrophobic Low Viscous Fatty Acid-Based Deep Eutectic Solvents. ACS Sustainable Chemistry \& Engineering. 2018;6(3):3888-95.

34. Gajardo-Parra NF, Cotroneo-Figueroa VP, Aravena P, Vesovic V, Canales RI. Viscosity of Choline Chloride-Based Deep Eutectic Solvents: Experiments and Modeling. Journal of Chemical \& Engineering Data. 2020;65(11):5581-92.

35. Chen J, Li X, Huang A, Deng W, Xiao Y. Nonionic surfactants based hydrophobic deep eutectic solvents for liquid-liquid microextraction of Sudan dyes in tomato chili sauces. Food Chemistry. 2021;364:130373.

36. Wang Y, Ma C, Liu C, Lu X, Feng X, Ji X. Thermodynamic Study of Choline Chloride-Based Deep Eutectic Solvents with Water and Methanol. Journal of Chemical \& Engineering Data. 2020;65(5):244657.

37. Pan T, Wang Z, Xu J-H, Wu Z, Qi H. Extractive fermentation in cloud point system for lipase production by Serratia marcescens ECU1010. Applied Microbiology and Biotechnology. 2010;85(6):178996.

38. Dhamole PB, Wang Z, Liu Y, Wang B, Feng H. Extractive fermentation with non-ionic surfactants to enhance butanol production. Biomass and Bioenergy. 2012;40:112-9.

39. Ritter E, Racheva R, Storm S, Müller S, Ingram T, Smirnova I. Influence of Inorganic Salts on the Phase Equilibrium of Triton X-114 Aqueous Two-Phase Systems. Journal of Chemical \& Engineering Data. 2016;61(4):1496-501.

40. Yamini Y, Feizi N, Moradi M. Chapter 7 - Surfactant-Based Extraction Systems. In: Poole CF, editor. Liquid-Phase Extraction: Elsevier; 2020. p. 209-39.

41. Fricke B. Quantitative determination of zwitterionic detergents using salt-induced phase separation of Triton X-100. Analytical biochemistry. 2000;281(2):144-50. 
42. Yu X, Li M, Yagoub AEA, Chen L, Zhou C, Yan D. Switchable (pH driven) aqueous two-phase systems formed by deep eutectic solvents as integrated platforms for production-separation 5-HMF. Journal of Molecular Liquids. 2021;325:115158.

43. Dharaiya N, Bahadur P. Phenol induced growth in Triton X-100 micelles: Effect of $\mathrm{pH}$ and phenols' hydrophobicity. Colloids and Surfaces A: Physicochemical and Engineering Aspects. 2012;410:81-90.

44. Iqbal M, Tao Y, Xie S, Zhu Y, Chen D, Wang X, et al. Aqueous two-phase system (ATPS): an overview and advances in its applications. Biological Procedures Online. 2016;18(1):18.

45. Jablonsky M, Butor Skulcova A, Russ A, Sima J. The pH Behavior of Seventeen Deep Eutectic Solvents. 2018;13.

46. Chandramohan M, Yee CY, Kei Beatrice PH, Ponnaiah P, Narendrakumar G, Samrot AV. Production, characterization and optimization of fibrinolytic protease from Bacillus pseudomycoides strain MA02 isolated from poultry slaughter house soils. Biocatalysis and Agricultural Biotechnology. 2019;22:101371.

47. Vijayaraghavan P, Rajendran P, Prakash Vincent SG, Arun A, Abdullah Al-Dhabi N, Valan Arasu M, et al. Novel Sequential Screening and Enhanced Production of Fibrinolytic Enzyme by<i> Bacillus</i>sp. IND12 Using Response Surface Methodology in Solid-State Fermentation. BioMed Research International. 2017;2017:3909657.

48. Cho Y-H, Song J, Kim K, Kim M, Lee I, Kim S, et al. Production of nattokinase by batch and fedbatch culture of Bacillus subtilis. New biotechnology. 2010;27:341-6.

49. Capela EV, Santos JHPM, Boal-Palheiros I, Coutinho JAP, Ventura SPM, Freire MG. A simple approach for the determination and characterization of ternary phase diagrams of aqueous two-phase systems composed of water, polyethylene glycol and sodium carbonate. Chem Eng Educ. 2019;53(2):112-20.

50. da Silva AV, do Nascimento JM, Rodrigues $\mathrm{CH}$, Silva Nascimento DC, Pedrosa Brandão Costa RM, de Araújo Viana Marques D, et al. Partial purification of fibrinolytic and fibrinogenolytic protease from Gliricidia sepium seeds by aqueous two-phase system. Biocatalysis and Agricultural Biotechnology. 2020;27:101669.

51. Teke GM, Pott RWM. Design and evaluation of a continuous semipartition bioreactor for in situ liquid-liquid extractive fermentation. Biotechnology and bioengineering. 2021;118(1):58-71.

52. Ali AMM, Bavisetty SCB. Purification, physicochemical properties, and statistical optimization of fibrinolytic enzymes especially from fermented foods: A comprehensive review. International Journal of Biological Macromolecules. 2020;163:1498-517.

53. Moon S-M, Kim J-S, Kim H-J, Choi MS, Park BR, Kim S-G, et al. Purification and characterization of a novel fibrinolytic $\alpha$ chymotrypsin like serine metalloprotease from the edible mushroom, Lyophyllum shimeji. Journal of Bioscience and Bioengineering. 2014;117(5):544-50.

54. Cruz Filho RFd, dos Santos JG, Palheta RA, Santos-Ebinuma VC, Viana Marques DdA, Teixeira MFS. Comparison of conventional and extractive fermentation using aqueous two-phase system to extract fibrinolytic proteases produced by Bacillus stearothermophilus DPUA 1729. Preparative biochemistry \& biotechnology. 2020:1-10. 
Figures

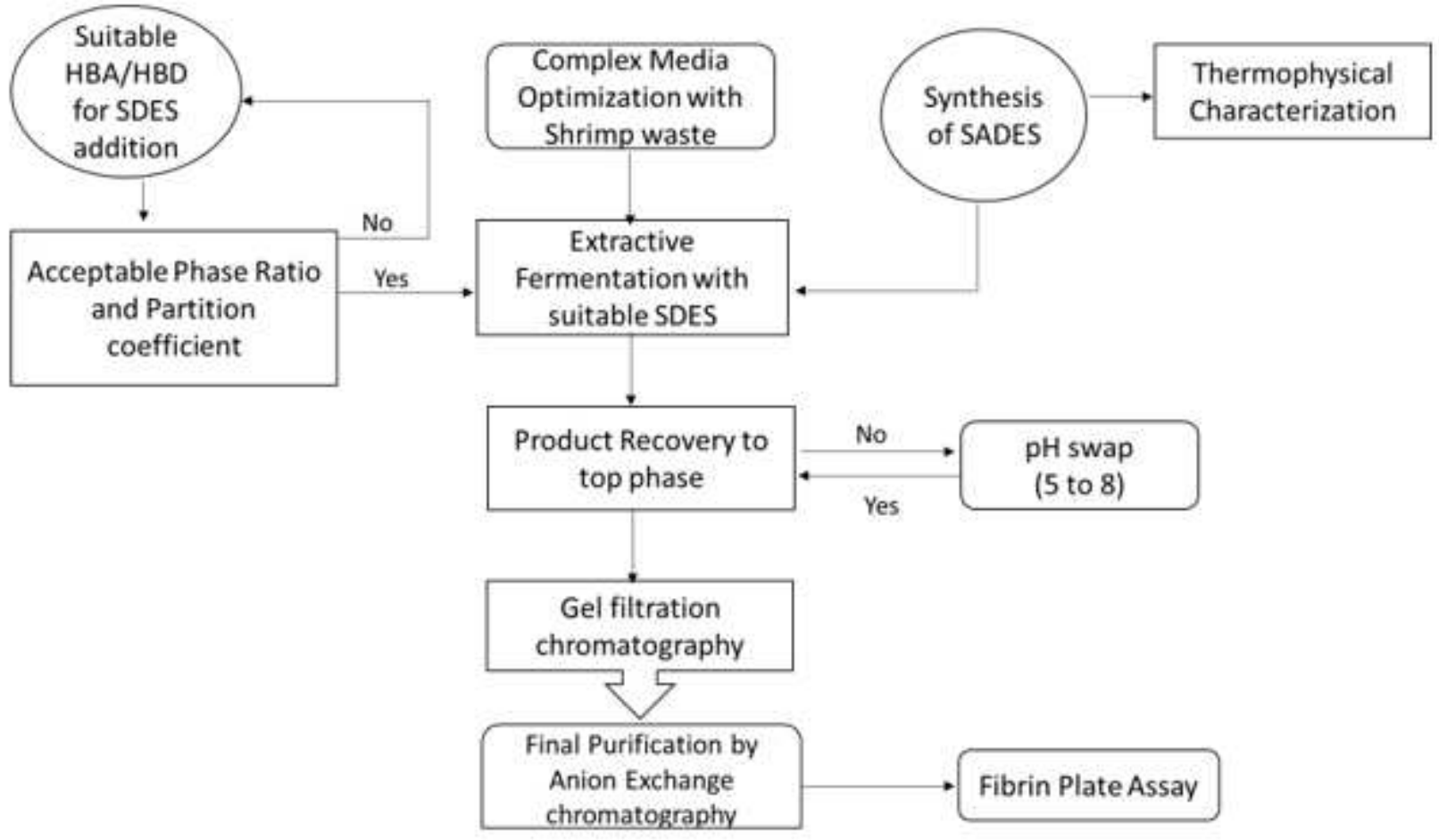

Figure 1

Schematic algorithm of swappable pH extractive fermentation for selective purification of fibrinolytic protease using surfactant based deep eutectic solvents (SDES) 
Non-lonic Surfactants

Triton $\times 100$
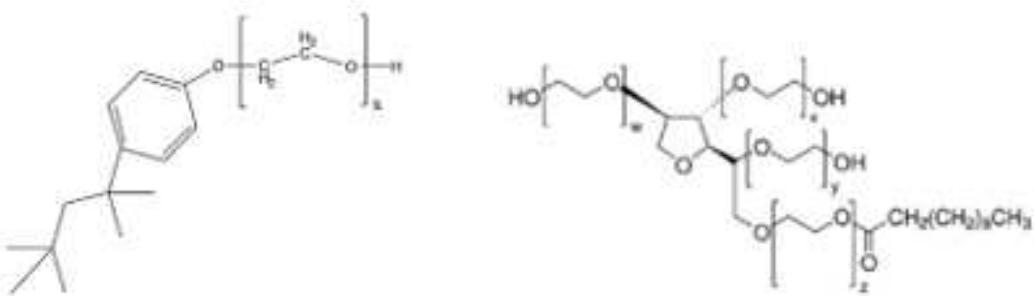

Tween 80
Choline chloride

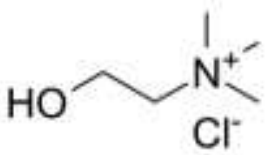

Quaternary ammonium salts

Tetra butyl ammonium bromide

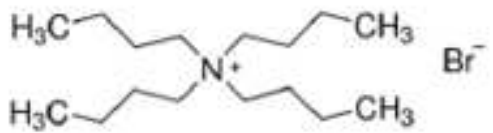

Tetra butyl ammonium chloride<smiles>CCCC[N+](CCCC)(CCCC)CCCC</smiles>

\section{Figure 2}

Structures of non-ionic surfactants acting as HBD and quaternary ammonium salts acting as HBA in formation surfactant based deep eutectic solvents (SDES) 

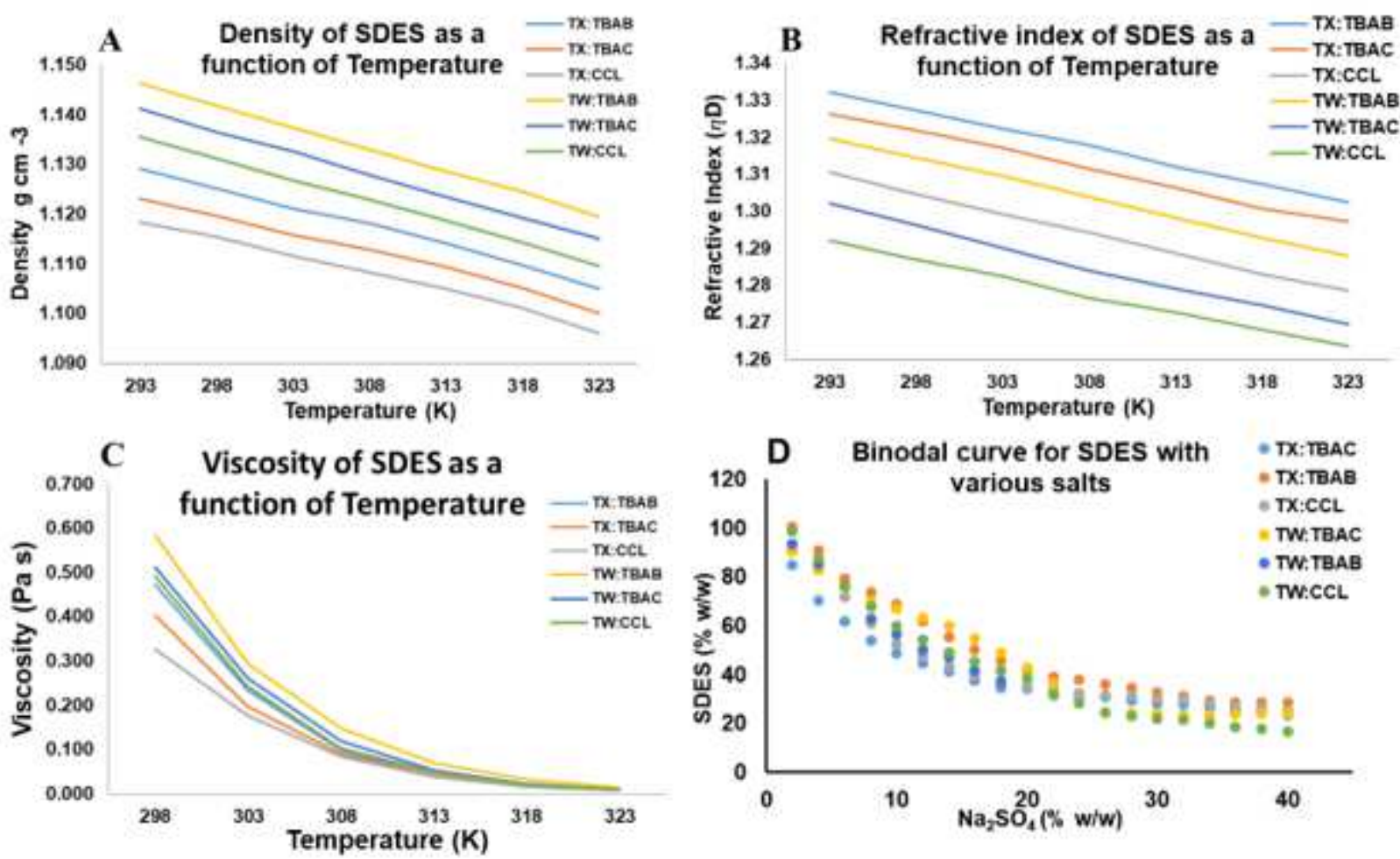

Figure 3

Density (A), Refractive index (B) and Viscosity (C) of different SADES subjected to temperature in the range of 293-323 K and (D) Binodal curve determination of various SADES with sodium sulphate.

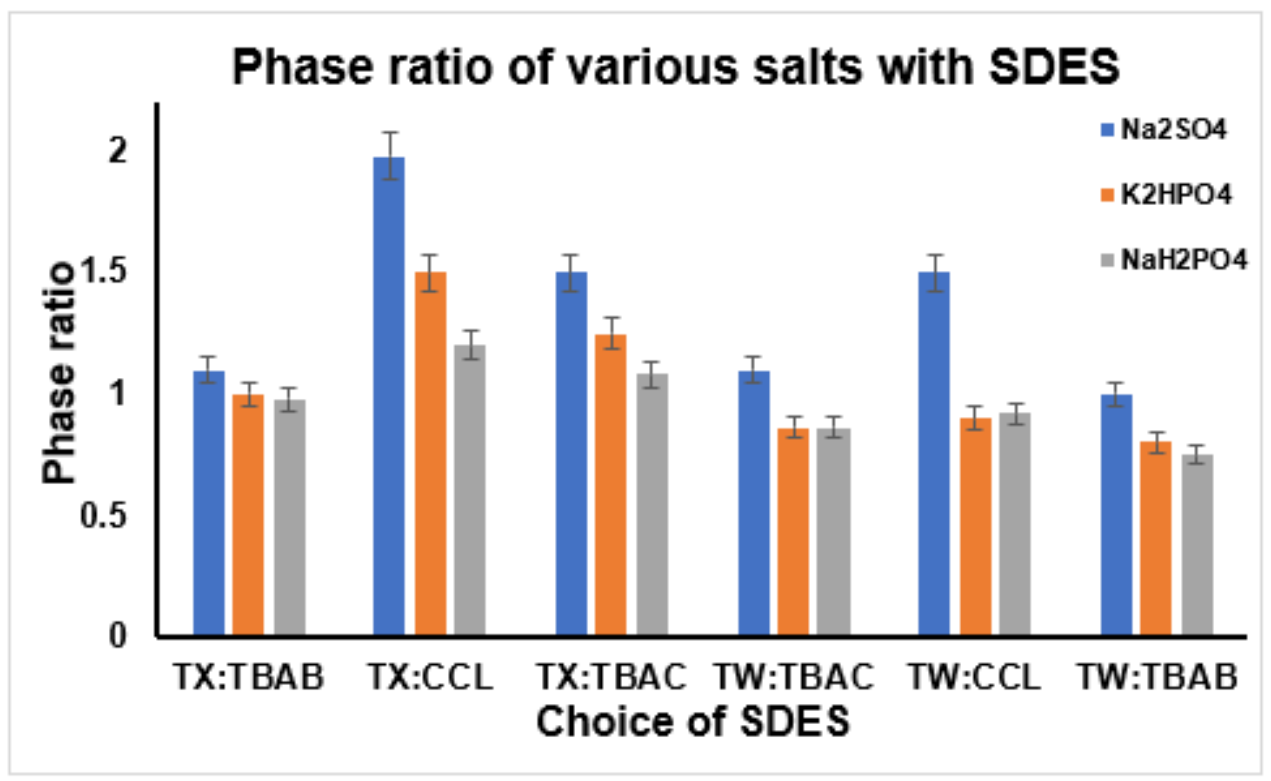

Figure 4

The partition coefficient values of various salts in combination with all six SDES under investigation 

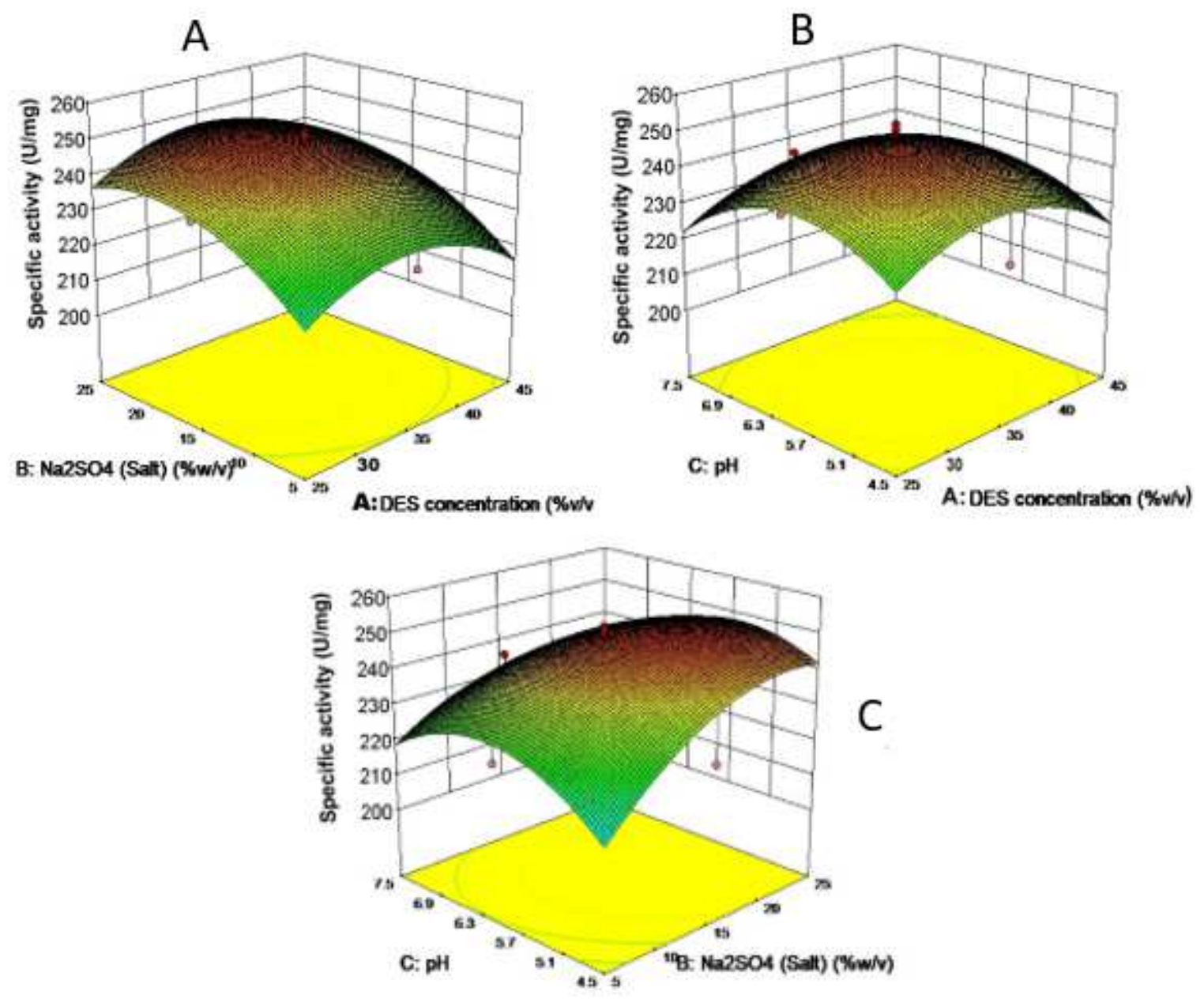

Figure 5

Response surface methodology based optimization of SDES concentration, Salt concentration and pH of medium for effective recovery of fibrinolytic protease. (A) denotes the cumulative effect of DES and salt concentration, (B) denotes the cumulative effect of $\mathrm{pH}$ and SDES concentration and (C) denotes the effect contributed by $\mathrm{pH}$ in combination with salt concentration for selective recovery of the enzyme. 


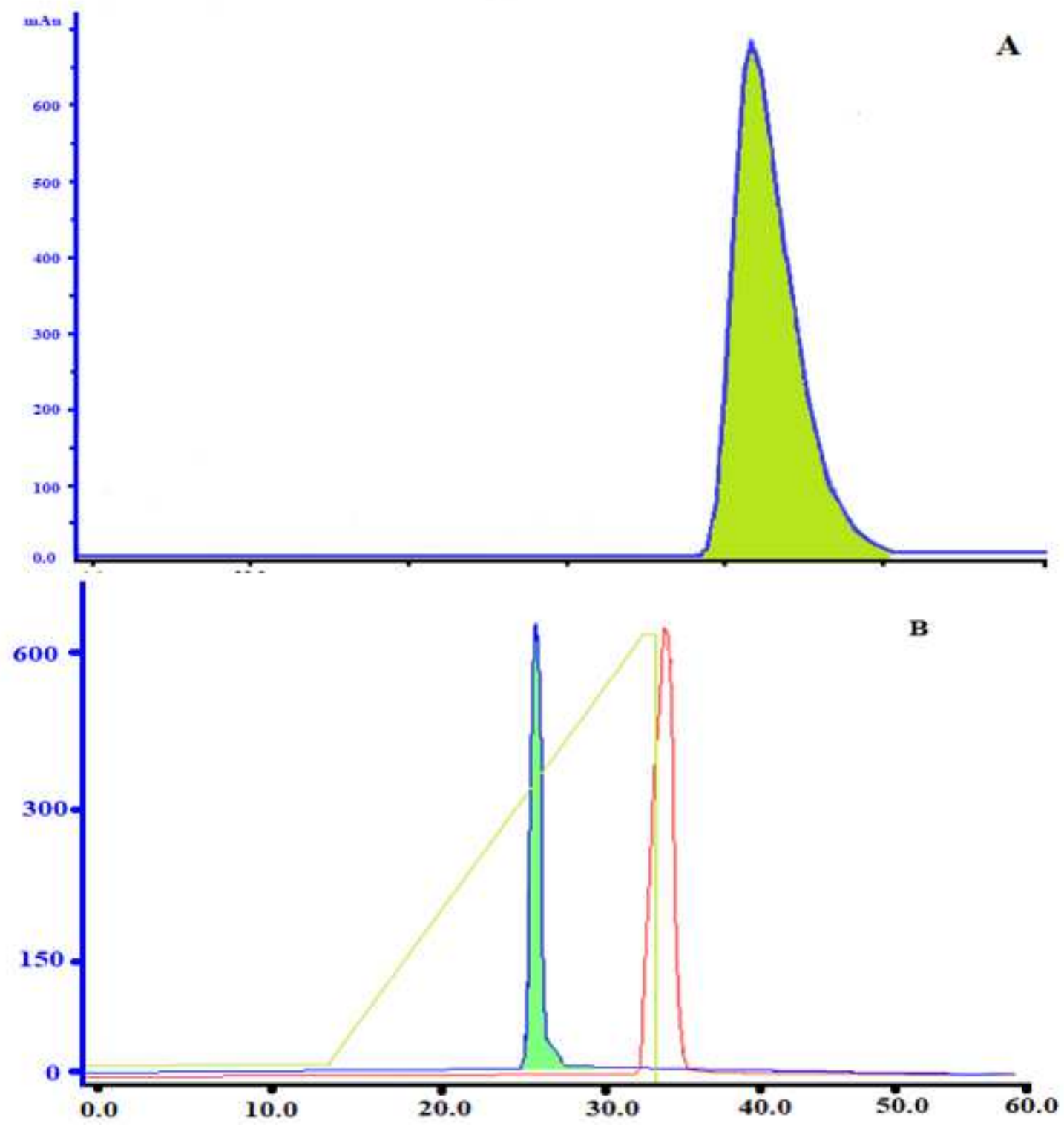

Figure 6

(A) Gel filtration chromatogram and (B) Anion exchange chromatogram obtained through purification of fibrinolytic protease obtained from extractive fermentation using surfactant based DES. 


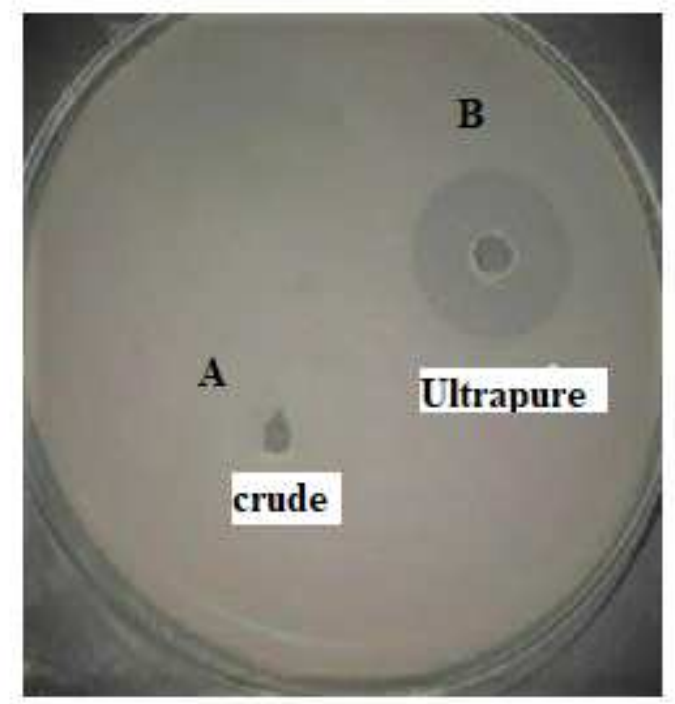

\section{Figure 7}

Fibrin plate assay for (A) crude fraction from micellar extractive fermentation and (B) Ultrapre fraction from anion exchange chromatography

\section{Supplementary Files}

This is a list of supplementary files associated with this preprint. Click to download.

- supplementary.docx 